\title{
Differences in Prioritization of the BSC's Strategic Goals Using AHP and ANP Methods
}

\author{
Aleksander Janeš \\ Faculty of Management \\ University of Primorska, Koper, Slovenia \\ aleksander.janes@fm-kp.si
}

Nikola Kadoić

Faculty of Organization and Informatics

University of Zagreb, Varaždin, Croatia

Nina Begičević Ređep

Faculty of Organization and Informatics

nbegicev@foi.hr

University of Zagreb, Varaždin, Croatia

\author{
University of Zagreb, Varazdin, Croatia
}

nkadoic@foi.hr

\begin{abstract}
The development and empirical verification of the balanced scorecard (BSC) model, using the multi-criteria decision-making methods (MCDM) called the analytic hierarchy process (AHP) and the analytic network process (ANP), are the key issues of the presented research. The paper presents the methodology of the prioritization of the BSC goals with the AHP and ANP methods. Even though the prioritization of the goals is possible with both, findings from the empirical analysis showed that the ANP is more complementary with the BSC because of the influences among the goals in the BSC. The ANP supports the modelling of those influences (through dependencies) and the AHP does not. The paper discusses special situations in prioritizing the BSC goals (understanding the ANP from the perspective of the user and the BSC with strategic goals that do not directly influence any other strategic goal) and proposes solutions. Therefore, it can be asserted that introducing the ANP to implement the BSC and vice versa, improved the decision-making approach and the quality of the obtained results. The research was based on a case study of modelling the BSC for Ydria Motors LL (YM), a manufacturing company.
\end{abstract}

Keywords: analytic hierarchy process, analytic network process, balanced scorecard, decision-making, performance measurement systems, strategy

\section{Introduction}

Organisations cannot successfully execute strategies if strategic analyses and formulations are poor [1]. Among the number of approaches for measuring business performance, several have attained a dominant position, e.g. analytic hierarchy process (AHP) [2], analytic network process (ANP) [3], [4] and balanced scorecard (BSC) [5]. 
The AHP is a theory of measurement using pairwise comparisons and relies on expert judgements to derive priority scales. The AHP helps analysts to organise theoretical aspects of a problem into a hierarchical structure, similar to a family tree. By reducing complex decisions to a series of simple comparisons and rankings, and then synthesising the results, the AHP helps analysts to arrive at the best decision, and provides them with a clear rationale for the choices made [6]. In addition to the AHP, the ANP is a useful tool for prediction and for representing a variety of competitors with their interactions and their relative strengths to wield influence in making decisions [4].

The ANP is employed to identify causal relationships [7] of a BSC's strategy map [8]. The inclusion of a BSC provides a framework to ensure that all important criteria are examined and the relevant ones are included in the decision model. The ANP provides a convenient means of including BSC indicator interactions and their prioritization [9]. Both methods support the decision-making process [4], and they have been used in combination with several additional statistical and managerial methods.

The specific objectives of this paper are the following:

- To briefly present AHP/ANP methods used in developing the AHP-BSC and ANP-BSC models.

- To compare the benefits of the proposed approach by combining the AHP and the ANP with the BSC.

- To present AHP-BSC and ANP-BSC models by means of a case study of the Ydria Motors LL Company (YM).

The remainder of the paper proceeds as follows. In Section 2, the conceptual background of the method used is presented. The methodology section (Section 3) presents construct operationalization and validation procedures. This section is followed by the data analysis and results section (Section 4), which discusses the testing of the proposed research methodology. The paper concludes with a discussion of the empirical findings and implications for research and practices (Sections 5 and $6)$.

\section{Conceptual background}

In the following section, brief descriptions of the AHP, ANP and BSC methods, as well as the state of the art on the topic, are presented.

\subsection{The Analytic Hierarchy Process and the Analytic Network Process methods}

The AHP provides a framework to cope with multiple criteria situations involving intuitive, rational, quantitative and qualitative aspects [10]. Hierarchical representation of a system can be used to describe how changes in priority at upper levels affect the priority of criteria at lower levels [11]. It organizes the basic rationality by breaking down a problem into smaller and smaller constituent parts, and then guides decision makers through a series of pairwise comparison judgments to 
express the relative strength or intensity of the impact of the elements on the hierarchy [12].

AHP was developed in 1972 as a practical approach in solving relatively complex problems [13]. AHP helps the analysts to organize theoretical aspects of a problem into a hierarchical structure similar to a family tree. By reducing complex decisions to a series of simple comparisons and rankings, and then synthesizing the results, the AHP not only helps the analysts to arrive at the best decision, but also provides them with a clear rationale for the choices made [14]. Due to its mathematical simplicity and flexibility, AHP has been a favourite decision tool for research in many fields, such as engineering, food, business, ecology, health and government. Wong and Li [15] applied AHP multi-criteria decision analysis f the selection of intelligent building systems. Singh's [16] study used the AHP approach to prioritize strategic areas and subfactors for a coordinated supply chain.

The AHP has certain limitations when the complexity of decision problems increases and interactions among criteria and sub-criteria are not implicitly covered [2], [4]. To avoid these limitations, generally known as the rank-reversal problem, the ANP was developed by considering the dependency and feedback among elements [17]. The ANP is recognised as an improved or general form of AHP, and it is capable of evaluating a wide range of criteria, including tangible and intangible factors that have a bearing on the outcome, without bothering about their linear hierarchy. The ANP allows for complex interactions and influences among the various components of the decision problem, thus making it a better choice for studying more complex decision problems. The ANP brings all of the decision objectives, criteria, alternatives and actors, e.g. decision makers, into a single unified framework, and it facilitates the interaction and feedback of elements within groups-clusters (inner dependence) and between groups-clusters (outer dependence).

The general steps of the AHP/ANP methods engagement [18], [6] and [19] are:

1. Decision-making problem structuring: Regarding the AHP, the decisionmaking problem is structured hierarchically and regarding the ANP, the decision-making problem is structured in the form of a network. At the top of the hierarchy is a decision-making goal, and criteria are at the second level. Below the criteria level are sub-criteria, and at the lowest level are alternatives. In the network, all decision-making elements (goal, criteria and alternatives) are presented as nodes in clusters. The main difference between hierarchy and network structure is that in the network, feedbacks are allowed (i.e., alternatives can depend on criteria, not only that criteria depend on alternatives). General hierarchy and network structures are presented in Figure 1.

The structuring procedure of AHP/ANP methods is the most crucial procedure in decision-making. It is important to cover all criteria relevant to the problem-solving, as well as to identify all dependencies among network elements. In order to perform successful structuring, methods, such as Delphi technique or other procedures, can be used [5].

2. Creating the unweighted supermatrix and filling it with priorities that came as the result of pairwise comparisons using Saaty's scale: Pairwise comparisons 
that have to be done are: (a) comparisons of criteria with respect to the goal; (b) comparisons of criteria that are influenced by the same criteria with respect to that criteria; (c) comparisons of the alternatives with respect to each criterion; and (d) comparisons of the criteria with respect to each criterion. All those sub-steps should be made with the ANP. In the AHP, only sub-steps, (a) and (c), have to be made because, in the hierarchy, there are no influences among criteria, as well as among the feedbacks from alternatives to criteria that caused sub-steps (b) and (d).

3. Creating the weighted supermatrix: Within this procedure, rows in each column with cluster priorities are to be multiplied. Cluster priorities come as the result of the pairwise comparison procedure of a cluster that is influenced by the same cluster.

4. Calculating the limit matrix: The weighted matrix is multiplied by itself, and this procedure repeats until the product matrix equals the factor matrix. The characteristic of the limit matrix is that all columns are the same. The values in rows represent the final priorities of nodes (alternatives and criteria).

5. Sensitivity analysis.
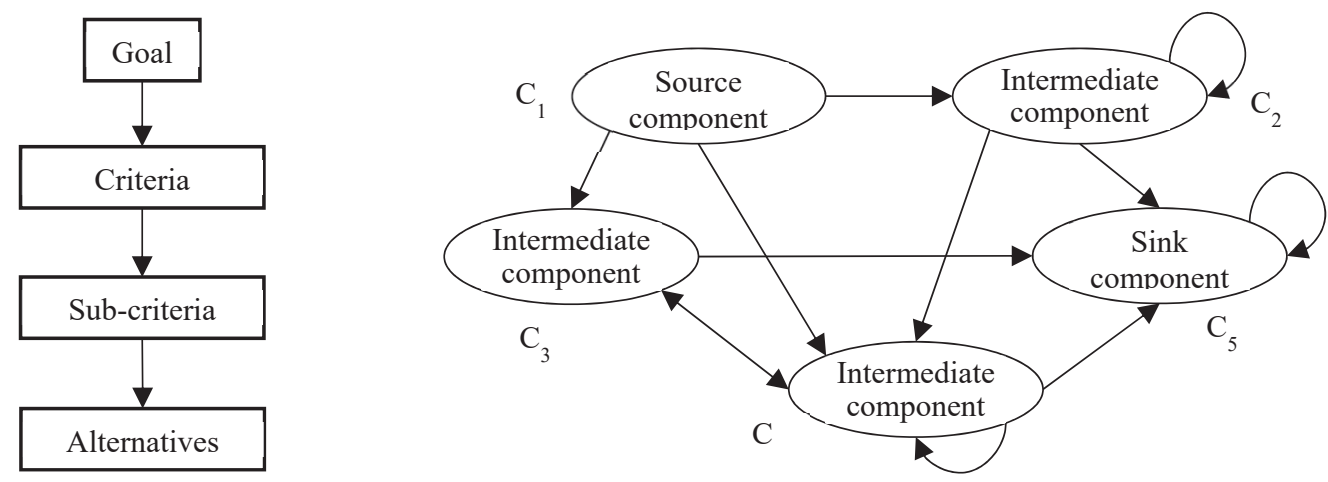

Figure 1. Structural difference between hierarchy and network (adapted from [20], [21])

The ANP can improve communication and resolve conflicts, help diffuse responsibility, and assist decision makers in understanding other members' viewpoints. These characteristics are attractive when a good decision calls for actions that may not be well liked, e.g., outsourcing and IT projects [4]. The ANP is competent enough to capture the interrelationships among the decision variables for prioritizing the various alternatives [22].

However, the method is built on the seven pillars of the AHP and serves as a starting point [23]. ANP draws attention to the AHP by incorporating interdependencies without a need to specify levels as in a hierarchy. ANP model building requires the definition of elements and their assignment to clusters, and a definition of their relationships (i.e., the connections indicating the flow of influence between the elements). Like AHP, ANP is also founded on a ratio scale measurement and pairwise comparisons of elements to derive priorities of selected alternatives [4]. 
The main function of the ANP is to determine the relationship of a network structure on the degree of interdependence. Once the measures are identified, the second most important question is the weight that should be given to each particular measure in designing the model. For example, the BSC's measures are derived from the interrelated strategic objectives of the organisation; hence, in deriving their weights, these relationships are quite useful [22]. Therefore, influence is a central concept in the ANP. It is a useful tool for prediction and representation, and for representing a variety of competitors with their surmised interactions and their relative strengths to wield influence in making decisions. When the decision-making process involves attributes that have a dependency relationship, the problem should be modelled as an ANP [23], [4]. Most complex real-world decision-making problems have numerous interdependent elements that can be captured and processed utilizing the feedback and interaction capabilities of an ANP model [24], [9].

According to Thakkar et al. [22], ANP is a multi-attribute decision-making approach, based on the knowledge, experience and perceptions of experts in the field. Even though it does not provide an optimal solution (from a cost perspective), it is valuable for decision-making, involving intangible attributes that are associated with strategic factors. The use of the ANP method provides the means to accommodate interrelationships of organizational objectives, for determining the weights for various BSC perspectives, and this makes the results more valuable and realistic.

Recently, contributors have applied the ANP in many managerial areas. Ravi, Shankar and Tiwari [25] combine the BSC and the ANP to conduct reverse logistics operations for end-of-life computers. Nakagawa and Sekitani [26] utilise the ANP for supplier selection [27] and supply chain performance evaluation [28]. Niemira and Saaty [29] use the ANP for financial crisis forecasting. Leung, Lam and Cao [3] use the AHP and the ANP to facilitate the implementation of the BSC. Gencer and Gürpinar [27] suggest that user-friendly software would help managers apply the ANP more easily in decision-making [30]. Wu and Lee [31] use the ANP for knowledge management strategy selection. Lin, Chiu and Tsai [32] utilise the ANP to find the most optimal dispatching method. The achievements of the ANP can be observed from its diverse applications and areas of usage, such as economics, business, benchmarking, education, manufacturing, project management [33], product development, sociology, politics etc. [34], [35], [36], [37], [38].

\subsection{The Balanced Scorecard}

The most important management decision-making issues are strategic planning, strategic analysis and the evaluation of strategy execution [1], [7], [70].

In practice, the top management evaluates the executives by their ability to execute strategy. However, managers struggle in closing the gap between strategy and actual results, which limits organizational growth, adaptability and competitiveness [39, p. 370], [73]. Among the number of approaches for measuring strategy execution, i.e., business performance, a dominant position was achieved by the BSC [5], [69]; it has emerged as a new synthesis between the traditional financial accounting system 
and efforts to achieve long-term competitive capability. In this way, it provides key information about the activities of the managers [7], [72].

In general, the steps of the strategic management (i.e., planning and performance measurement) of an organization with the BSC are [40], [41], [42], [43], [44]:

1. Defining the strategic elements of the organisation: These include the values, vision (generally for three years), mission and destination statement. The destination statement supports the verification of selected strategic goals, indicators (measures) and their targets and initiatives, as well as their impact on changes in the organisation [45], [71].

2. Defining strategic themes: The strategic themes stem from the vision of the organisation. In addition, strategic themes represent the decomposition of overall strategy because they contain its basic parts, define business processes that add value to customers and enable the classification of strategic goals [5], [46], [72].

3. Defining strategic goals and their classification within strategic themes: This is a description of what needs to be done at the strategic level so that the chosen vision of the organisation is met. The set of strategic goals can therefore be developed on the basis of a destination statement or with conducting a strengths, weaknesses, opportunities, and threats (SWOT) analysis for each strategic goal.

4. Creating a diagram of usually four perspectives: This can be used to classify strategic goals in terms of financial and non-financial perspectives and the internal and external perspectives of the organisation [43], [69].

5. Determining the causal links between the strategic goals and the identification of the strategic map: The causal links between strategic goals move in the direction from the learning and growth perspective and extend all the way to the financial perspective [5], [46], [71]. Different authors also suggested the use of several methods for the qualitative analysis, such as interviews with experts, the Delphi technique, brainstorming and Decision Making Trial and Evaluation Laboratory (DEMATEL) [47], [48], [49], [50], [70].

6. Validation and empirical verification of the BSC: This can be performed with different types of software packages, e.g., Dialog strategy ${ }^{1}$, [51], [63] in order to validate the extent to which the model matches the reality.

Despite its many benefits, the BSC approach has several critical deficiencies.

The BSC lacks dynamics, since it does not properly consider the effect of the dynamics existing within a system. The BSC literature makes a clear distinction between two types of performance indicators: the lagging (financial KPIs) and the leading (performance driver KPIs). In other words, a key element in correctly specifying causal relationships is to consider their time dimension and magnitude [52, p. 453].

Furthermore, regardless of the prioritization and importance of the identification of the BSC's elements, the BSC still critically lacks resource allocation consideration.

\footnotetext{
${ }^{1}$ The software is available through website http://www.dialogsoftware.com/.
} 
Since budgets and resources of organisations are limited, organisations cannot execute all proposed strategic initiatives which have critical impact on the organisational vision and mission. Therefore, organisations must identify and select the most viable strategic activities, as well as cost-beneficial projects, for optimizing the resource application. There are some existing linkages between resource allocation and strategic management under the BSC approach (e.g., [55], [56]); nevertheless, the BSC, along with its improved approaches, still has not taken into consideration the limited resources of organisations. Therefore, the improvement of this issue will provide a practical strategic management approach in real-life managerial situations [8], [57, pp. 1703-1704], [70], [73].

Next deficiency is manifested as tangible "proxies", such as defect and absenteeism rates and customer satisfaction surveys, which are used to capture the intangible attributes [7]. Moreover, objective surrogate measures often inaccurately reflect intangible criteria. Nonetheless, subjective evaluations are vulnerable to accusations of favouritism or other kinds of abuses, whereas objective measures may be perceived as more fair and transparent.

Another critical consideration is how the weights of the subjective and objective criteria should be determined if both types of criteria are used in the BSC [3, pp. 683, 688]. Therefore, a number of researchers, authors and scholars have tried to resolve some of the aforementioned deficiencies by applying multi-criteria decision-making (MCDM) methods, such as the technique for order of preference by similarity to ideal solution (TOPSIS), AHP or ANP. MCDM methods have distinctiveness in fitting to the weaknesses and complexities of BSC, especially multiple criteria consideration (e.g., [53], [54], [69]). Hence, AHP has been empirically identified to add several advantages to $\mathrm{BSC}$, such as multi-criteria prioritization, comparative analysis of business performance and qualitative and quantitative determination. Nevertheless, for numerous applications, there are still some criticisms as far as the integration of BSC and AHP is concerned, specifically for the lack of dependency consideration within the BSC's dimensions and indicators. It seems reasonable to suggest that the more complex the interactions, the greater the need to utilize the ANP [3, p. 683], [71]. This MCDM concept has distinctive identities that fit the BSC above other methods, as the ANP could consider qualitative or quantitative data and also dependency among elements for the entire model [57, pp. 1706-1707].

An ANP model consists of a network of nodes which are grouped into clusters. In the case of ANP modelling, clusters represent the perspectives of a BSC, nodes represent the strategic goals and arcs represent the cause-effect relationships. It should be noted that the arcs in the ANP model are in the opposite direction from those in the strategy map (see Figures 2 and 4). The objective of the method is to find those causal relationships between the strategic goals. To do this, the method starts with a network that includes all possible arcs, and then those which are not important are eliminated from the goal network, resulting in a strategy map of the organisation [58, p. 1093].

Using the ANP/AHP alone without the aid of the BSC, the decision maker might develop a model with an incomplete set of decision criteria and/or with some of the criteria being repeated. The inclusion of the BSC [73] provides a framework to ensure that all important criteria are examined and the relevant ones are included in the 
outsourcing decision model. The ANP provides a convenient means of including the $\mathrm{BSC}$ indicator interactions and prioritizing the BSC indicators [9]. Moreover, the algorithm for the ANP accounts for all of the performance measures included in the BSC. This alleviates the negative influence of judgment biases when decision makers use the BSC as part of their performance management [59].

\section{Methodology: Prioritization of the BSC goals using AHP and ANP}

The inclusion of the BSC provides a framework to ensure that all important criteria are examined and that the relevant ones are included in the decision model [58], [9].

The methodological approach used in the presented research was based on a comprehensive review of academic and grey literature, a pool of the existing models, meta-analysis and a number of executive managers' consultations. Further, it was based on background research, a literature review and an analysis of AHP, ANP and BSC characteristics.

The research was performed as a case study of modelling the BSC system for a manufacturing company and founded on the complementary use of qualitative and quantitative methods. The strategic map of the company that contains the causal relationships between its strategic goals and their respective KPIs has been set and confirmed with the executive management [60], [7]. The proposed approach uses the ANP/AHP and aims at identifying the causal relationships of a BSC. Basically, what the method does is estimate the importance of the relationships, and then selects those relationships that are considered important according to executive management [60], [7], [8]. In this section, the general methodology for prioritization of the BSC goals using AHP and ANP is presented. The case study of BSC goals prioritization of the YM Company is presented in following section.

The research's objective was to analyse the benefits of the proposed approach of combining the ANP/AHP and BSC methods. The methodology was performed using the following steps [58], [57]:

1. With qualitative analysis and the designed BSC system [7], [5], a startingpoint, i.e., identification of the strategic objectives, for the quantitative analysis was prepared. The identified strategic map of the YM Company is presented in Figure 2.

2. Considering that the AHP method does not include influences among goals, influences were eliminated from the identified BSC model. Therefore, since each AHP model starts from the goal at the top of the model's hierarchy, the AHP-BSC model of the investigated case is designed as seen in Figure 3.

3. Prioritization of the BSC's goals using the AHP method was performed. Pairwise comparisons on each level of structure (generally, there are two levels) were carried out. The objective was to obtain the importance of all nodes of one cluster in relation to every node of all other clusters.

4. The ANP-BSC model was designed. Since the ANP method includes dependencies among criteria in the consideration (not influences directly), first we converted the current BSC's strategic map into a model with dependencies. Secondly, in terms of the ANP decision-making problem, the 
current BSC model was truncated. One of the characteristics of decisionmaking with the ANP is the inseparability of criteria and alternatives. In this case, if goals represent "criteria level", then the "alternative level" is missing. In terms of Step 4 (Calculating the limit matrix) of the ANP method, that means that some BSC goals will have priority 0 (e.g., if some criterion/BSC goal has no influence on any other). To avoid this, we proposed a variant of adding a fictive alternatives cluster with only one node (Alt). Therefore, each BSC goal was connected with an alternative node in order to obtain feedbacks (the alternative was not connected with all the BSC goals). That ensured that each BSC goal had at least one graph-walk in which it was a source and destination (none of the goals would have the priority 0). The ANP-BSC model is presented in Figure 4.

5. Prioritization of the BSC goals by using the ANP corresponded to Steps 2 (creating the unweighted supermatrix and filling it with priorities) and 3 (creating the weighted supermatrix) from Subsection 2.1. The comparisons that were done included pairwise comparisons of goals from the same cluster with respect to the goal, as well as pairwise comparisons of the clusters - the AHP part. On the other hand, the comparisons that had to be done were pairwise comparisons of the BSC goals that were influenced by the same goal and, less often, pairwise of clusters that are influenced by the same cluster (perspective). All pairwise comparisons that in some way included an alternative node (and alternative cluster) were not done: as we said, this alternative cluster/node is fictive and this node must not contribute to any node in terms of pairwise comparisons. The procedure of criteria pairwise comparisons with respect to other criteria (in this case, comparisons of the goals with respect to other goals) is often very complex, time-consuming and difficult for the users to understand [61], [62], [19], but this procedure can be enhanced in two ways [20]:

a. Firstly, intensities of influences between goals can be defined as a part of the BSC (identification of the strategic objectives). If so, those intensities can be normalized to 1 and directly incorporated in an unweighted supermatrix.

b. Secondly, if intensities of the influences between goals are not defined as a part of the BSC, we can define them now by using, for example, the DEMATEL scale $(0=$ no influence, $1=$ weak influence, $2=$ medium influence, $3=$ high influence and $4=$ very high influence). After a weighted BSC map of goals is created using the matrix of transition [20, p. 184, then the unweighted supermatrix can be easily filled.

6. Comparison of the results from Steps 3 (Prioritization of the BSC goals using the AHP) and 5 (Prioritization of BSC goals using the ANP), as well as the comparison of the procedures of prioritization of the BSC goals by using the AHP and the ANP, were performed. In terms of comparing the results of two methods, Spearman's rank correlation was calculated. To compare the 
procedures of the prioritization, differences in terms of complexity and duration were presented.

\begin{tabular}{|c|c|c|c|}
\hline No. & Step & Methods & Output \\
\hline 1 & $\begin{array}{l}\text { Design of } \\
\text { Strategic map } \\
\text { of the } \\
\text { organization }\end{array}$ & $\begin{array}{l}\text { Qualitative analysis } \\
\text { Interviews with experts (management } \\
\text { board of the organization) } \\
\text { Literature review }\end{array}$ & $\begin{array}{l}\text { Strategic map of goals } \\
\text { (organization's goals } \\
\text { associated to BSC } \\
\text { perspectives } \\
\text { influences among them. } \\
\text { Sometimes, intensities } \\
\text { of the influences are } \\
\text { also defined) }\end{array}$ \\
\hline 2 & $\begin{array}{l}\text { Design of the } \\
\text { AHP-BSC } \\
\text { model }\end{array}$ & $\begin{array}{l}\text { Converting BSC perspectives to DM } \\
\text { criteria on the first level of the AHP } \\
\text { model } \\
\text { Joining organization's goals to } \\
\text { belonging DM criteria in AHP model }\end{array}$ & $\begin{array}{l}\text { AHP-BSC model of } \\
\text { organization's goals }\end{array}$ \\
\hline 3 & $\begin{array}{l}\text { AHP } \\
\text { prioritization }\end{array}$ & Conducting the AHP & $\begin{array}{l}\text { Organization's goals } \\
\text { priorities by AHP }\end{array}$ \\
\hline 4 & $\begin{array}{l}\text { Design of the } \\
\text { ANP-BSC } \\
\text { model }\end{array}$ & $\begin{array}{l}\text { Converting influences } \\
\text { dependencies } \\
\text { (DEMATEL) } \\
\text { (Adding a fictive alternative) }\end{array}$ & $\begin{array}{l}\text { ANP-BSC model of } \\
\text { organization's goals }\end{array}$ \\
\hline 5 & $\begin{array}{l}\text { ANP } \\
\text { prioritization }\end{array}$ & $\begin{array}{l}\text { Conducting the ANP } \\
\text { (Normalisation of predefined } \\
\text { intensities (if case) of influences } \\
\text { between goals to 1, per each } \\
\text { organization's goal) } \\
\text { (Normalisation of DEMATEL } \\
\text { intensities to 1 per each organization's } \\
\text { goal: normalisation by sum or using } \\
\text { the matrix of transition) }\end{array}$ & $\begin{array}{l}\text { Organization's goals } \\
\text { priorities by ANP }\end{array}$ \\
\hline 6 & $\begin{array}{l}\text { Comparing } \\
\text { AHP and ANP } \\
\text { priorities }\end{array}$ & Spearman rank correlation & $\begin{array}{l}\text { Differences in AHP and } \\
\text { ANP priorities }\end{array}$ \\
\hline
\end{tabular}

Table 1. Methodology for prioritization of the BSC goals using AHP and ANP (methods in brackets - column 3 - are optional)

Additionally, it is possible to upgrade the prioritization of the BSC goals with analysis of benefits, opportunities, costs and risks (BOCR).

The specifics of the presented methodology are as follows:

1. The possibility of using the fictive node of alternatives in the prioritization of the BSC goals by using the ANP method (Step 4: Designing the ANP-BSC model). If we apply "regular" ANP to prioritize the BSC goals, depending on connections among goals, in some cases, it is possible that some goals will have priority 0 . That might lead us to the conclusion that they are (equally) unimportant. To avoid that, we introduced a fictive alternative node. This 
node would get some priority after applying the ANP, but we excluded it from interpretation.

2. Identifying the intensities of the influences among the BSC goals in order to decrease the complexity and duration of the ANP-BSC procedure (Step 5: Prioritization of the BSC goals using the ANP).

\section{Case study: Prioritization of the BSC goals of the YM Company}

In this section, application of the methodology from Section 3 is presented. The YM Company is organised as a competence centre that produces and develops machines, appliances and electric motors for home appliances.

\subsection{Creating BSC strategic map of goals}

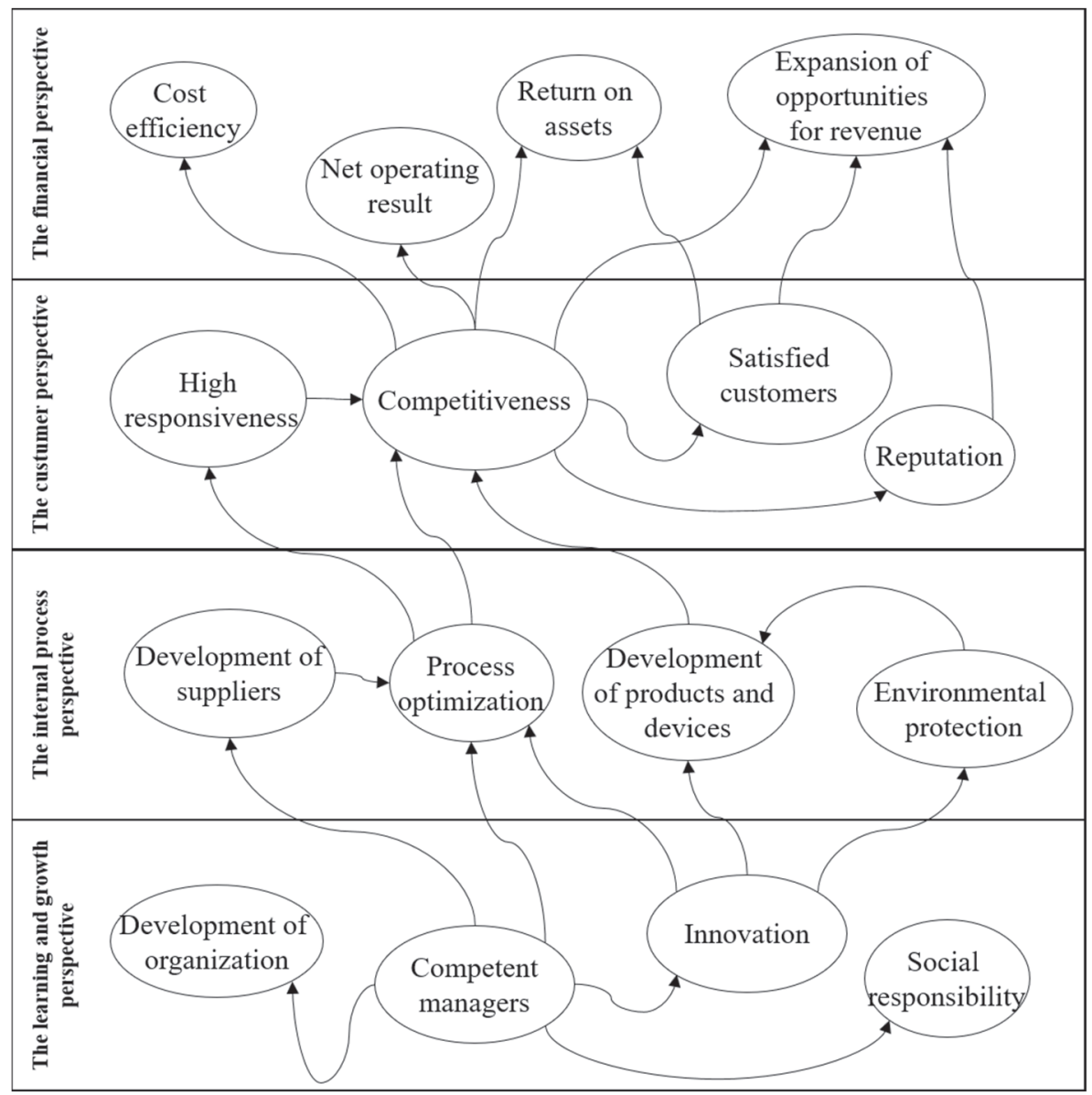

Figure 2. Strategic map of the YM Company (Source: Adapted from Janeš, 2014 [7])

The company's understanding of its business performance sustainability, which is based on comprehensive data tests and semi-structured interviews with three of the 
YM Company's executive managers, contributed to the selection of the strategic goals in the BSC's perspectives. The strategic goals are arranged according to importance as stated by the executive management in the following sequence:

1. Financial perspective: Expansion of opportunities for revenue (Revenue), Cost efficiency, Net operating result and Return on assets (ROA).

2. Customer perspective: Competitiveness, High responsiveness, Reputation and Satisfied customers.

3. Internal process perspective: Development of products and devices (Development of PD), Process optimisation, Development of suppliers and Environmental protection.

4. Learning and growth (LG) perspective: Competent managers, Organisation development, Innovation and Social responsibility.

The BSC strategic goals (nodes) and their respective relationships (arcs) are presented in Figure 2.

\subsection{Designing the AHP-BSC model and prioritization of BSC goals using the AHP method}

The AHP-BSC model of the YM Company was designed according to the methodology and presented in Section 3 (Figure 3).

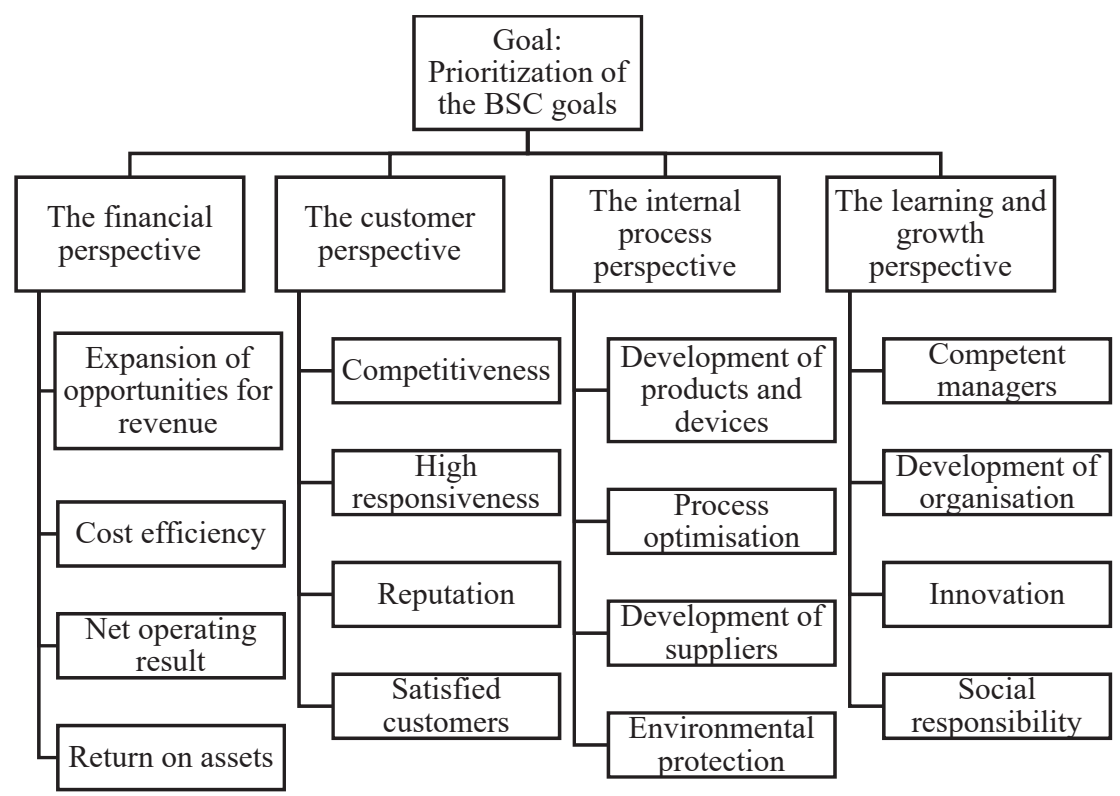

Figure 3. AHP-BSC model of the YM Company

After the pairwise comparisons were done, the priorities of the BSC goals were obtained. The strategic goals are arranged according to importance as stated by the all three members of the executive management [66], [67]. The model was designed with 
the Super Decisions software [68]. As presented in Table 1, the greatest priority (0.46730) belonged to the strategic goals of the Expansion of opportunities for revenue and the Development of products and devices. Those priorities are followed by Competent managers and Development of organisation with a priority of 0.38493 . The first three of those strategic goals had the highest priorities according to the executive managers (see Figure 3).

\begin{tabular}{|l|l|}
\hline BSC Goal & Priority \\
\hline Goal & 0.00000 \\
\hline Competitiveness & 0.35112 \\
\hline High responsiveness & 0.35112 \\
\hline Reputation & 0.13682 \\
\hline Satisfied customers & 0.16095 \\
\hline Cost efficiency & 0.27718 \\
\hline Expansion of opportunities for revenue & 0.46730 \\
\hline Net operating result & 0.16009 \\
\hline Return on assets & 0.09544 \\
\hline Development of products and devices & 0.46730 \\
\hline Development of suppliers & 0.16009 \\
\hline Environment protection & 0.09544 \\
\hline Process optimization & 0.27718 \\
\hline Competent managers & 0.38493 \\
\hline Development of organisation & 0.38493 \\
\hline Innovation & 0.14279 \\
\hline Social responsibility & 0.08735 \\
\hline
\end{tabular}

Table 2. Priorities of the BSC goals of the YM Company (AHP)

The strategic goals of Competitiveness and High responsiveness, the most important goals in the Customer's perspective, achieved a priority of 0.35112 . Other strategic goals achieved somewhat lower priorities, as can be seen in Table 1.

\subsection{Designing the ANP-BSC model and prioritization of BSC goals using the ANP method}

The initial ANP model consisted of five perspectives (clusters), which included strategic goals (nodes) with cause-effect relationships (arcs). The modelling process only considered relationships on the basis of grounded cause-effect relationships among the strategic goals. The cluster, Vision, and its node, Stakeholders, have been substituted for the Goal and fictive cluster Alternatives. The model is designed based on the Super Decisions [68] simple network template (see Figure 4). Since in the BSC, the influences are modelled and in ANP, dependencies are modelled, arrows from Figure 2 have to be changed (turned). Additionally, dependencies from decisionmaking goal to each BSC element have are inserted. Also, the dependencies in both directions between each BSC goal and fictive alternative node are inserted. 


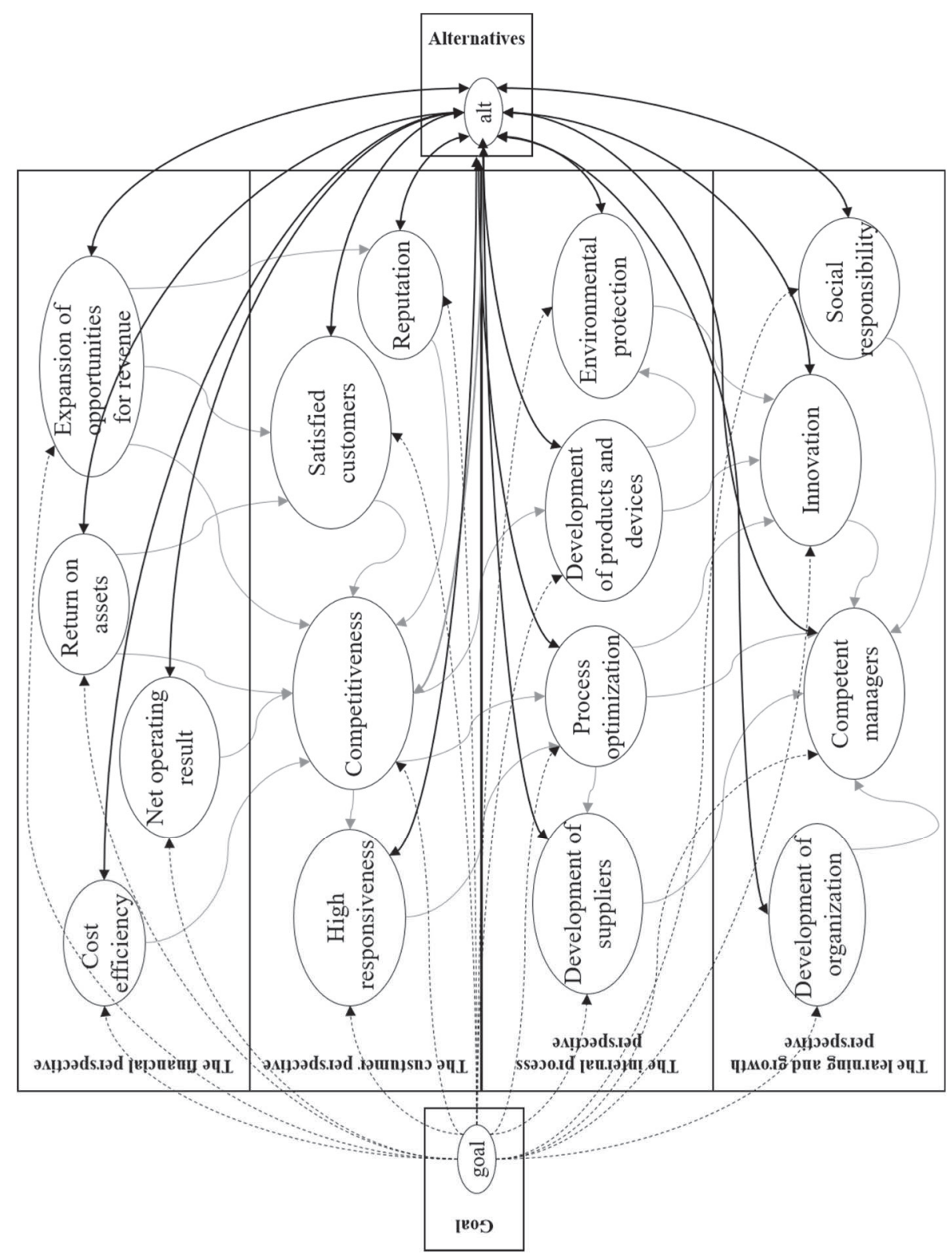

Figure 4. ANP model with nodes and arcs

In the next step, pairwise comparisons between nodes were carried out in order to obtain priorities. Pairwise comparisons were collected from the experts, i.e., with the involvement and consensus of the executive management involved in developing the ANP-BSC model [66] and with the used Super Decisions [68] software. An example of the comparisons matrix of the strategic goals (nodes) is presented in Table 2. For each comparisons matrix, the inconsistency ratio was calculated, which was under the expected level of 0.1 . To this end, the pairwise comparisons for the nodes in each 
cluster that belong to a parent node were carried out for all the parent nodes in the model. In the presented research, all clusters that represent the BSC perspectives are equally important. Thereafter, the unweighted and weighted matrixes were calculated.

\begin{tabular}{|l|c|c|c|c|}
\hline & $\begin{array}{c}\text { Cost } \\
\text { efficiency }\end{array}$ & $\begin{array}{c}\text { Net operating } \\
\text { result }\end{array}$ & $\begin{array}{c}\text { Return on } \\
\text { assets }\end{array}$ & Revenue \\
\hline Cost efficiency & 1.0 & 2 & 3 & 0.5 \\
\hline Net operating result & 0.5 & 1.0 & 2 & 0.3333 \\
\hline Return on assets & 0.3333 & 0.5 & 1.0 & 0.25 \\
\hline Revenue & 2 & 3.0 & 4 & 1.0 \\
\hline
\end{tabular}

Table 3. Comparisons matrix of the financial perspective strategic goals in the ANP model

In the presented simple, straightforward network of clusters, nodes and arcs, the process of obtaining the limit matrix is performed in order to raise the weighted supermatrix to powers until it stabilises, i.e., until all the columns in the matrix have the same values so the priorities of all nodes can be read from any column (Table 3 ).

\begin{tabular}{|l|c|c|}
\hline \multicolumn{1}{|c|}{ BSC goal } & $\begin{array}{c}\text { Priority (ANP with } \\
\text { the fictive } \\
\text { alternative) }\end{array}$ & $\begin{array}{c}\text { Priority } \\
\text { (ANP) }\end{array}$ \\
\hline Goal & 0 & 0 \\
\hline Competitiveness & 0.146856913 & 0.114685 \\
\hline High responsiveness & 0.105409421 & 0.100878 \\
\hline Reputation & 0.029297625 & 0.017267 \\
\hline Satisfied customers & 0.018581240 & 0.016959 \\
\hline Cost efficiency & 0.037630020 & 0.019279 \\
\hline Expansion of opportunities for revenue & 0.063438841 & 0.032502 \\
\hline Net operating result & 0.021733663 & 0.011135 \\
\hline Return on assets & 0.012955331 & 0.006638 \\
\hline Development of products and devices & 0.090350933 & 0.061306 \\
\hline Development of suppliers & 0.053100499 & 0.077584 \\
\hline Environment protection & 0.012955331 & 0.006638 \\
\hline Process optimization & 0.094102053 & 0.132899 \\
\hline Competent managers & 0.172752144 & 0.278212 \\
\hline Development of organisation & 0.052256459 & 0.026773 \\
\hline Innovation & 0.076721295 & 0.091169 \\
\hline Social responsibility & 0.011858232 & 0.006076 \\
\hline
\end{tabular}

Table 4. Priorities of the BSC goals by using ANP with the fictive alternative and ANP

The cluster, Goal, and its node, Goal, were added to ensure that nodes from the same perspective were mutually compared in pairs, and that the clusters were compared in pairs with respect to the Goal. The fictive cluster, Alternatives, and its node, Anode, were added to enhance alternatives and, therefore, are not considered in the analysis (in terms of priorities).

In the case of ANP with the fictive alternative (Table 3), the Financial cluster with its nodes, Expansion of opportunities for revenue (0.063438841), Cost efficiency 
(0.037630020), Net operating result (0.021733663) and ROA (0.012955331), appears to have a relatively minor priority according to the limit matrix, which is not the case according to the interviews with the executive managers. The results from the limit matrix indicate that, in the Customer cluster, the highest priority belongs to the node Competitiveness (0.146856913), which is the second most important node among all nodes. Competitiveness is followed by High responsiveness (0.105409421). This result is in accordance with the importance stated by the executive management. Reputation (0.029297625) and Satisfied customers (0.018581240) appear to have a relatively lower priority, which aligns somewhat with the company's ranking of the nodes. In the Internal process cluster, the highest priority node is Process optimization (0.094102053), followed by Development of products and devices $(0.090350933)$, Development of suppliers (0.053100499), which is not entirely in accordance with the importance stated by the executive management. In their opinion, the most important strategic goal in the Internal process perspective is Development of products and devices. Environmental protection has a low priority of 0.012955331. In the Learning and growth cluster, the highest priority node is Competent managers $(0.172752144$ is the highest priority among all strategic goals) followed by Innovation $(0.076721295)$, which surpassed Development of organisation (0.052256459). Organisation development is at the second level of importance according to executive management. Social responsibility has, according to management, a low priority (0.011858232).

In the case of the ANP without the fictive alternative, the priorities are somewhat lower, but show similar results. Namely, the strategic goal Competent managers has the highest priority (0.278212) among all strategic goals, even in comparison with the ANP with the fictive alternative. The next to follow Competent managers is the strategic goal of Process optimization (0.132899), followed by Competitiveness (0.114685) and High responsiveness (0.100878).

Even though applying the "regular" ANP to prioritize the BSC goals resulted in no criterion with priority 0 , applying the ANP with the fictive alternative node was unnecessary. However, application of the ANP with the fictive alternative node was performed to evaluate this procedure. In the next subsection, Spearman's rank correlation of the ANP and ANP with the fictive alternative will be calculated for evaluation.

\subsection{Comparison of the results of prioritization of goals in BSC using ANP and AHP}

In order to compare the analysis results (priorities) of the BSC goals by using the AHP and ANP methods, Spearman's rank correlation was calculated [64]. The results are presented in Table 5 .

From results of the three Spearman's rank correlations, it can be concluded that ranks of the priorities with the ANP and ANP with the fictive alternative are very good (0.978) because the ranks are highly correlated. It is important that this rank correlation is high so that the results of the ANP with the fictive alternative can be considered as correct. 
On the other hand, rank correlations of the AHP with ANP including the fictive alternative (0.771) and the AHP with ANP (0.692) are good, but there are differences. Those differences were expected because the ANP method is capable of calculation of the influences among the criteria. The priorities which resulted from the application of the ANP method are more acceptable because of its capability that enables it to be more complementary with the BSC.

\begin{tabular}{|l|r|r|r|r|r|r|}
\hline BSC goal & \multicolumn{1}{|l|}{$\begin{array}{l}\text { Rank } \\
\text { (ANPf) }\end{array}$} & $\begin{array}{l}\text { Rank } \\
\text { (ANP) }\end{array}$ & $\begin{array}{l}\text { Rank } \\
\text { (AHP) }\end{array}$ & $\begin{array}{l}\text { anpf/ } \\
\text { anp }\end{array}$ & \multicolumn{1}{l}{$\begin{array}{l}\text { anpf/ } \\
\text { ahp }\end{array}$} & \multicolumn{1}{l}{$\begin{array}{l}\text { anp/ } \\
\text { ahp }\end{array}$} \\
\hline Goal & 17 & 17 & 17 & 0 & 0 & 0 \\
\hline Competitiveness & 2 & 3 & 5 & 1 & 9 & 4 \\
\hline High responsiveness & 3 & 4 & 5 & 1 & 4 & 1 \\
\hline Reputation & 11 & 11 & 13 & 0 & 4 & 4 \\
\hline Satisfied customers & 12 & 9 & 1 & 16 & 9 \\
\hline Cost efficiency & 10 & 7 & 0 & 9 & 9 \\
\hline $\begin{array}{l}\text { Expansion of opportunities for } \\
\text { revenue }\end{array}$ & 7 & 8 & 1 & 1 & 36 & 49 \\
\hline Net operating result & 12 & 13 & 10 & 1 & 4 & 9 \\
\hline Return on assets & 14 & 14 & 14 & 0 & 0 & 0 \\
\hline $\begin{array}{l}\text { Development of products and } \\
\text { devices }\end{array}$ & 5 & 7 & 1 & 4 & 16 & 36 \\
\hline Development of suppliers & 8 & 6 & 10 & 4 & 4 & 16 \\
\hline Environment protection & 14 & 14 & 14 & 0 & 0 & 0 \\
\hline Process optimization & 4 & 2 & 7 & 4 & 9 & 25 \\
\hline Competent managers & 1 & 1 & 3 & 0 & 4 & 4 \\
\hline Development of organisation & 9 & 9 & 3 & 0 & 36 & 36 \\
\hline Innovation & 6 & 5 & 12 & 1 & 36 & 49 \\
\hline Social responsibility & 16 & 16 & 16 & 0 & 0 & 0 \\
\hline
\end{tabular}

Table 5. Spearman's rank correlation results

\section{Practical implications of the ANP-BSC model}

One of the main areas that both the relevant literature and Kaplan and Norton themselves identified as critical is related to the identification, assessment and quantification of causal relationships which are essential within the BSC [52], [65]. In this context, the causal relationships have been at the centre of survey interest because they provide a better relationship model among the four BSC perspectives and their respective strategic goals, which are defined in a subjective way. Even though this way of working is widely accepted in practice, some studies have shown that the declared relationships are not necessarily valid. In order to overcome this situation, the proposed ANP provides a quantitative tool in order to establish the relationships among strategic objectives [7], [58], [61], [19]. After the semi-structured interviews with the managers, they established that the designed strategy map represented the company's strategy (Figure 2) [7]. 
It should be noted that the arcs (Figure 4) were changed in the opposite direction from the BSC model cause-effect relationships. The ANP model indicated that, if the managers' competencies and the development of suppliers were improved, then the process optimisation and labour productivity might improve. Similarly, to improve the customers' satisfaction, it is necessary to improve the competitiveness of the optimised production processes.

The advantage of using the ANP is that it allows for the inclusion of dependence and feedback on the strategic goals and perspectives in the strategic map. From a practical point of view, the presented method is a good alternative for designing a strategy map of a company, which uses an ANP approach that has been successful in many other areas of management. Therefore, it opens new possibilities for research. It should be noted that the presented ANP approach is in accordance with the findings of the Engle-Granger two-step method approach used in previous research performed by Janeš [7].

In continuation qualitative analysis (discussion) for the AHP and ANP, prioritization application of the BSC's goals is represented. Analysis of possible modifications of the ANP in terms of the prioritization of BSC goals is also considered:

1. Inclusion of influences in goals prioritizing support: The AHP does not support influences, but the ANP (with its modifications) does.

2. Complexity (number of comparisons): The number of comparisons in the ANP method and its modifications are higher because pairwise comparisons of the BSC goals, with respect to other BSC goals that influence them, have to be done. In an AHP conducted on a weighted graph of influences among BSC goals, the number of pairwise comparisons remains the same.

3. Duration: The AHP has the shortest duration, and the ANP has the longest. In the case of the ANP conducted over the weighted strategic map of the BSC goals, duration falls somewhere in between that of both methods used (We have to insert weights on the graph of influences, but do not have to do pairwise comparisons of the goals with respect to other BSC goals that influence them).

4. Understanding the procedure: As mentioned above, the procedure of comparing the $\mathrm{BSC}$ goals with respect to the goal that influences them is often difficult for users to understand. For that reason, application of the ANP over a weighted graph is the most appropriate option.

5. Dealing with the BSC goals that do not influence any other BSC goal: In this case, the best analysis option is the ANP with the fictive alternative cluster and goal.

Based on the qualitative analysis, it can be concluded that the best option for the BSC goals prioritization depends on the specific case and the experience with the ANP method of the decision maker. If the decision maker is acquainted with the ANP, but does not understand the pairwise comparisons of goals with respect to the third one, the best choice is to make a weighted strategic map of goals and automatize the ANP (which means avoiding those pairwise comparisons). If the BSC contains strategic goals that do not influence any other strategic goal, it is advisable to use the ANP with 
the fictive alternative. Finally, if the decision maker is not familiar with the ANP, there is always the opportunity of using the AHP method.

\section{Conclusions}

The literature has identified the necessity to further define the concept of causality within the layout of the BSC in the direction of relying on specific quantitative tools needed to convert the BSC into a mathematical model. Therefore, based on the reviewed literature, the main characteristics of this approach have been depicted, and, in particular, the potentialities of using the AHP/ANP methods to explore the concept of causality in the BSC have been stressed.

A key finding in this research is that the development of the BSC, supported by the ANP, contributes to the explanation of causal relationships in the BSC system. However, it must be emphasised that the generalisation of the research findings was limited to only one manufacturing company. Based on the results, it is recommended that further research be oriented towards expanding the ANP-BSC to other companies, and to use the causal relationships to forecast the future trajectory of the strategy in order to generalise findings and acquire new knowledge.

\section{Acknowledgements}

This paper has been supported by the Croatian Science Foundation under the project entitled "Development of a methodological framework for strategic decision-making in higher education - A case of open and distance learning (ODL) implementation". Project number: IP-2014-09-7854. Details about the project can be found at the project website: http://higherdecision.foi.hr/en.

\section{References}

[1] L. G. Hrebiniak, "Obstacles to effective strategy implementation," Organ. Dyn., vol. 35, no. 1, pp. 12-31, 2006.

[2] T. L. Saaty, The Analytic Hierarchy Process, New York: McGraw-Hill, 1980.

[3] L. C. Leung, K. C. Lam, and D. Cao, "Implementing the balanced scorecard using the analytic hierarchy process \& the analytic network process," J. Oper. Res. Soc., vol. 57, no. 6, pp. 682-691, 2006.

[4] T. L. Saaty, Decision Making with Dependence and Feedback: The Analytic Network Process. Pittsburgh, PA, USA: RWS Publications, 2001.

[5] R. S. Kaplan and D. P. Norton, Strategy Maps: Converting Intangible Assets into Tangible Outcomes. Boston, MA, USA: Harvard Business School Publishing, 2004. 
[6] T. L. Saaty, "Decision making with the analytic hierarchy process," Int. J. Services Sciences, vol. 1, no. 1, pp. 83-98, 2008.

[7] A. Janeš, "Empirical verification of the balanced scorecard," Industrial Management \& Data Systems, vol. 114, no. 2, pp. 203-219, 2014.

[8] F. Rahimnia and N. Kargozar, "Objectives priority in university strategy map for resource allocation,” Benchmarking: An. Int. J., vol. 23, no. 2, pp. 371-387, 2016.

[9] Y. Tjader, J. H. May, J. Shang, L. G. Vargas, and N. Gao, "Firm-level outsourcing decision making: A balanced scorecard-based analytic network process model," Int. J. of Production Economics, vol. 147, pp. 614-623, Jan 2014.

[10] P. Alberto, "The logistics of industrial location decision: An application of the analytical hierarchy process methodology," Int. J. of Logistics:

Research and Application, vol. 3, no. 3, pp. 273-289, 2000.

[11] F. T. S. Chan, "Interactive selection model for supplier selection process: An analytical hierarchy process approach," Int. J. of Production Research, vol. 41, no. 15, pp. 3549-3579, 2003.

[12] T. L. Saaty and K. P. Kearns, Analytical Planning: The Organization of Systems. Oxford: Pergamon Press, 1985.

[13] T. L. Saaty, "How to make a decision: The analytic hierarchy process," European J. of Operational Research, vol. 48, no. 1, pp. 9-26, 1990.

[14] K.S. Chin, S. Chiu, and V. M. R. Tummala, "An evaluation of success factors using the AHP to implement ISO 14001-based ESM," Int. J. of Quality \& Reliability Management, vol. 16, no. 4, pp. 341-61, 1999.

[15] J. K. W. Wong, H. Li, “Application of the analytic hierarchy process (AHP) in multi-criteria analysis of the selection of intelligent building systems," Building and Environment, vol. 43, no. 1, pp. 108-25, 2008.

[16] R. K. Singh, "Prioritizing the factors for coordinated supply chain using analytic hierarchy process (AHP)," Measuring Business Excellence, vol. 17, no. 1, pp. 80-97, 2013.

[17] S. Sipahi and M. Timor, "The analytic hierarchy process and analytic network process: An overview of applications," Management Decision, vol. 48, no. 5, pp. 775-808, 2010.

[18] T. L. Saaty and B. Cillo, A Dictionary of Complex Decision Using the Analytic Network Process, The Encyclicon, Volume 2, 2nd ed. Pittsburgh, PA, USA: RWS Publications, 2008.

[19] N. Kadoić, N. B. Ređep, and B. Divjak, "A new method for strategic decision-making in higher education,” Cen. Eur. J. of Oper. Res., Special 
Issue of Croatian Operational Research Society and Collaborators, Oct. 2017.

[20] N. Kadoić, N. Begičević Ređep, and B. Divjak, "Decision Making with the Analytic Network Process," SOR 2017 Conference, Bled, Ljubljana, 2017.

[21] T. L. Saaty and L. G. Vargas, Decision Making with the Analytic Network Process: Economic, Political, Social and Technological Applications with Benefits, Opportunities, Costs and Risks. Softcover reprint of hardcover 1st ed. (December 28, 2009). Springer, 2006.

[22] J. Thakkar, S. G. Deshmukh, A. D. Gupta, and R. Shankar, "Development of a balanced scorecard," Int. J. of Productivity and Performance Management, vol. 56, no. 1, pp. 25-59, 2006.

[23] T. L. Saaty, Decision Making for Leaders, Pittsburgh, PA, USA: RWS Publications, 1999.

[24] T. L. Saaty and M. Ozdemir, The Encyclicon: A Dictionary of Decisions with Dependence and Feedback Based on the Analytic Network Process, Pittsburgh, PA, USA: RWS Publications, 2004.

[25] V. Ravi, R. Shankar, and M. K. Tiwari, “Analyzing alternatives in reverse logistics for end-of-life computers: ANP and balanced scorecard approach," Computers \& Industrial Engineering, vol. 48, pp. 327-356, 2005.

[26] T. Nakagawa and K. Sekitani, "A use of analytic network process for supply chain management," Asia Pacific Management Review, vol. 9, no. 5, pp. 783-800, 2004.

[27] C. Gencer and D. Gürpinar, "Analytic network process in supplier selection: A case study in an electronic firm," Appl. Math. Model., vol. 31, pp. 2475-86, 2007.

[28] S. Jharkharia and R. Shankar, "Selection of logistics service provider: An analytic network process (ANP) approach,” Omega, vol. 35, pp. 274-289, 2007.

[29] M. P. Niemira and T. L. Saaty, "An analytic network process model for financial-crisis forecasting," Int. J. of Forecasting, vol. 20, pp. 573-87, 2004.

[30] N. Kadoić, N. Begičević Ređep, and B. Divjak, "E-learning decision making: Methods and methodologies," In Re-Imaging Learning Environments, A. Moreira Teixeira, A. Szucs, and I. Mázár (Eds.), Proceedings of the European Distance and E-Learning Network 2016 Annual Conference Budapest, 14-17 June, 2016, pp. 73-82. 
[31] W. W. Wu and Y.T. Lee, "Selecting knowledge management strategies by using the analytic network process," Expert Syst. Appl., vol. 32, pp. 841$847,2007$.

[32] Y. H. Lin, C. C. Chiu, and C. H. Tsai, "The study of applying ANP model to assess dispatching rules for wafer fabrication," Expert Syst. Appl., vol. 34, pp. 2148-2163, 2008.

[33] E. W. L. Cheng and H. Li, “Analytic network process applied to project selection,” J. Constr. Eng. Manag., vol. 131, no. 4, pp. 459-466, 2005.

[34] N. Begičević, B. Divjak, and T. Hunjak, "Comparison between AHP and AMP: Case study of strategic planning of e-learning implementation," In Proceedings of the ISAHP 2007, Viña Del Mar, Chile, August 3-8, 2007, pp. $1-10$.

[35] R. J. Kuo and Y. J. Lin, "Supplier selection using analytic network process and data envelopment analysis," Int. J. Prod. Res., vol. 50, no. 11, pp. 2852-2863, 2012.

[36] M. Moalagh and A. Z. Ravasan, "Developing a practical framework for assessing ERP post implementation success using fuzzy analytic network process," Int. J. Prod. Res., vol. 51, no. 4, pp. 1236-1257, 2013.

[37] M. Tavana, E. Momeni, N. Rezaeiniya, S. M. Mirhedayatian, and H. Rezaeiniya, "A novel hybrid social media platform selection model using fuzzy ANP and COPRAS-G," Expert Syst. Appl., vol. 40, no. 14, pp. 5694-5702, 2013.

[38] R. Wudhikarn, N. Chakpitak, and G. Neubert, "An analytic network process approach for the election of green marketable products," Benchmarking: An Int. J., vol. 22, no. 6, pp. 994-1018, 2015.

[39] A. Kumar Srivastava, and Sushil, "Modelling drivers of adapt for effective strategy execution," The Learning Organization, vol. 21, no. 6, pp. 369$391,2014$.

[40] R. S. Kaplan, "Conceptual foundations of the balanced scorecard," Handbooks of Management Accounting Research, vol. 3, pp. 1253-1269, 2009.

[41] Z. Dobrovic, M. Tomicic, N. Vrcek, Ž. Dobrović, M. Tomičić, and N. Vrček, "Towards the effective e-government implementation of balanced scorecard in public sector," Intelektine Ekonomika, vol. 8011, no. 1, pp. 7$17,2008$.

[42] J. Brumec, M. Tomičić, and S. Brumec, "Konstrukcija mjernih instrumenata za balanced scorecard," in Proceedings of 18th Conference on Methods and Tools for Information and Business Systems Development, pp. 21-30, 2006. 
[43] M. Hladchenko, "Balanced scorecard - a strategic management system of the higher education institution," International Journal of Educational Management, vol. 29, no. 2, pp. 167-176, Mar. 2015.

[44] M. Tomičić-Furjan, "Razvoj metodike mjerenja organizacijske učinkovitosti uporabom metamodeliranja," University of Zagreb, Faculty of Organization and Informatics, PhD Dissertation 2016.

[45] I. Cobbold, G. Lawrie, and K. Issa. "Designing a strategic management system using the third-generation balanced scorecard: A case study," Int. J. of Productivity and Performance Management, vol. 53, no. 7, pp. 624-633, 2004.

[46] R. S. Kaplan, and D. P. Norton, Alignment: Using the Balanced Scorecard to Create Corporate Synergies, Boston, MA, USA: Harvard Business School Publishing, 2006.

[47] D. Sumrit and P. Anuntavoranich, "Using DEMATEL method to analyze the causal relations on technological innovation capability evaluation factors in Thai technology-based firms," International Transaction Journal of Engineering, Management, \& Applied Sciences \& Technologies, vol. 4, no. 2, pp. 81-103, 2013.

[48] J. Shao, M. Taisch, M. Ortega, and D. Elisa, "Application of the DEMATEL method to identify relations among barriers between green products and consumers," 17th European Roundtable on Sustainable Consumption and Production - ERSCP 2014, pp. 1029-1040, 2014.

[49] R. Attri, N. Dev, and V. Sharma, "Interpretive structural modelling (ISM) approach : An overview," Research Journal of Management Sciences, vol. 2, no. 2, pp. 3-8, 2013.

[50] Y. Shih-Hsi, C. C. Wang, L. Y. Teng, and Y. M. Hsing, “Application of DEMATEL, ISM, and ANP for key success factor (KSF) complexity analysis in R\&D alliance," Scientific Research and Essays, vol. 7, no. 19, pp. 1872-1890, 2012.

[51] N. Kadoić, N. Begičević Ređep, and B. Divjak, "Structuring e-learning multi-criteria decision making problems," in Proceedings of 40th Jubilee International Convention, MIPRO 2017, 2017, pp. 811-817.

[52] F. Barnabè, "A system dynamics-based balanced scorecard to support strategic decision making: Insights from a case study," Int. J. of Productivity and Performance Management, vol. 60, no. 5, pp. 446-473, 2011.

[53] H.C. Huang, C.L. Lai, and L.H. Lin, "Developing strategic measurement and improvement for the biopharmaceutical firm: Using the BSC hierarchy," Expert Syst. Appl., vol. 38, no. 5, pp. 4875-4881, 2011. 
[54] A. V. Bentes, J. Carneiro, J. F. Silva, and H. Kimura, "Multidimensional assessment of organizational performance: Integrating BSC and AHP," J. of Business Research, vol. 65, no. 12, pp. 1790-1799, 2012.

[55] P. R. Niven, "Driving focus and alignment with the balanced scorecard," The Journal for Quality and Participation, vol. 28, no. 4, pp. 21-25, 2005.

[56] R. K. Kalamo. (2012). "The balanced scorecard as a connection between strategic and operational management." [Online]. Available: http://evstmobility.eu/projectuploads/42/Balanced\%20Scorecard\%20as $\% 2$ 0connection $\% 20$ between $\% 20$ strategic $\% 20$ and $\% 20$ operational $\% 20$ manage ment

[57] R. Wudhikarn, "An efficient resource allocation in strategic management using a novel hybrid method," Management Decision, vol. 54, no. 7, pp. 1702-1731, 2016.

[58] L. E. Quezada, P.I. Palominos, R. E Galleguillos, and A.H. Olmedo, “A method for generating strategy maps using ANP," J. of Manufacturing Technology Management, vol. 25, no. 8, pp. 1090-1104, 2014.

[59] Y. Hu, J. Wen, and Y. Yan, "Measuring the performance of knowledge resources using a value perspective: Integrating BSC and ANP," J. of Knowledge Management, vol. 19, no. 6, pp. 1250-1272, 2015.

[60] U.S. Bititci, K. Mendibil, S. Nudurupati, P. Garengo, and T. Turner, "Dynamics of performance measurement and organisational culture," Int. J. of Operations \& Production Management, vol. 26, no. 12, pp. 13251350, 2006.

[61] N. Kadoić, B. Divjak, and N. Begičević Ređep, "Effective strategic decision making on open and distance education issues," in EDEN Annual Conference 2017 Diversity Matters!, pp. 224-234, 2017.

[62] T. L. Saaty and N. Begičević, "The scope of human values and human activities in decision making," Appl. Soft Comput., vol. 10, pp. 963-974, 2010 .

[63] N. Kadoić, "Citizen participation in decision making processes in Croatian local government units," International Journal of Science and Engineering Investigations, vol. 6, no. 60, 2017.

[64] "Spearman rank correlation coefficient," in The Concise Encyclopedia of Statistics, New York, NY, USA: Springer, 2005, pp. 502-505.

[65] M. Jerman, S. Kavčič, and B. Kavčič, "The significance of intangibles: A comparative analysis between Croatia, Slovenia, Czech Republic, Germany and the USA," Ekonomska istraživanja, vol. 23, no. 2, pp. 60-69, 2010 . 
[66] A. Janeš, N. Kadoić, and N. Begičević Ređep, “The ANP representation of the BSC," In Proceedings of the CECIIS 2017, Varaždin, Croatia, September 27-29, 2017, pp. 309-315.

[67] N. Begičević, B. Divjak, and T. Hunjak, “AHP based group decision making using keypads," International Journal of Economics and Business Research, vol. 3, no. 4, 2011.

[68] B. Adams, Creative Decision foundation, "Super Decisions Software v. 2.6.0-RC1," 19, January, 2016. Available: https://superdecisions.com/downloads/.

[69] M. Hudnurkar, U. Rathod, S. Kumar Jakhar, and O. S. Vaidya, "Development of a balanced scorecard-based supplier collaborative performance index," International Journal of Productivity and Performance Management, vol. 67, no. 2, pp.401-425, 2018.

[70] C. Valmohammadi, and J.Sofiyabadi, "Modeling cause and effect relationships of strategy map using fuzzy DEMATEL and fourth generation of balanced scorecard," Benchmarking: An International Journal, vol. 22, no. 6, pp.1175-1191, 2015.

[71] S. Thanki, and J. Thakkar, "A quantitative framework for lean and green assessment of supply chain performance," International Journal of Productivity and Performance Management, vol. 67, np. 2, pp. 366-400, 2018.

[72] R. S. Kaplan, "The balanced scorecard: comments on balanced scorecard commentaries," Journal of Accounting \& Organizational Change, vol. 8, no. 4, pp. 539-545, 2012.

[73] M. L. Tseng, M. Lim, and W. P. Wong, "Sustainable supply chain management: A closed-loop network hierarchical approach," Industrial Management \& Data Systems, vol. 115, no. 3, pp.436-461, 2015. 